\title{
Novel patterns of physical activity in a large sample of preschool-aged children
}

\author{
Rachel M. Ruiz ${ }^{1}$, Evan C. Sommer ${ }^{2}$, Dustin Tracy ${ }^{3}$, Jorge A. Banda ${ }^{4}$, Christina D. Economos ${ }^{5}$, Megan M. JaKa ${ }^{6}$, \\ Kelly R. Evenson ${ }^{7}$, Maciej S. Buchowski ${ }^{8}$ and Shari L. Barkin ${ }^{*}$
}

\begin{abstract}
Background: Moderate-to-vigorous physical activity (MVPA), shown to be associated with health benefits, is not well-characterized in preschool-aged children. MVPA is commonly described as a threshold amount to achieve. We examined a novel way to characterize MVPA patterns in preschool-aged children by gender and age.

Methods: Preschool-aged children from Nashville, TN and Minneapolis, MN wore triaxial accelerometers. Four distinct MVPA patterns were identified: isolated spurt (IS), isolated sustained activity (ISA), clustered spurt (CS), and clustered sustained activity (CSA). Multivariable linear regression models were used to test associations of gender and age with each pattern.

Results: One thousand one hundred thirty-one children (3.9 years old, 51\% girls, 30\% overweight, 11\% obese, and $76 \%$ Hispanic) wore accelerometers for $12.9(S D=1.4)$ hours/day for $6.7(S D=0.7)$ days. Children spent $53 \%$ of wear time in sedentary behavior and $13 \%$ in MVPA. On average, boys and girls achieved $>90$ min/day of MVPA (98. 2 min, SD = 32.3). Most MVPA (80\%) was obtained in spurt-like (IS and CS) MVPA; however, girls spent a higher proportion of MVPA in IS and CS, and lower proportion of time in CSA (all $p<0.001)$. Controlling for gender, an increase of 1-year in age corresponded to a 1.5\% increase in CSA $(p<0.05)$.

Conclusions: How MVPA was obtained varied depending on the gender and age of the child. On average, boys spent more time in sustained MVPA than girls and MVPA was more sustained in older children. Utilizing these patterns could inform PA practice and policy guidelines.
\end{abstract}

Trial registration: NCT01316653, date of registration: March 3, 2011; NCT01606891, date of registration: May 23, 2012.

Keywords: Physical activity, Childhood obesity, Prevention, Family, MVPA, Latino, Parent and child

\section{Background}

The National Academy of Medicine recommends that toddlers and preschool-aged children be provided with opportunities for light, moderate, and vigorous PA for at least $15 \mathrm{~min} / \mathrm{h}$ [1]. This is equivalent to at least $3 \mathrm{~h} /$ day of total PA, similar to international guidelines [2-4]. Nationally representative PA data are not currently available for preschool-aged children; however, a recent US study provides evidence that nearly $60 \%$ of preschool-aged children do not meet this guideline [5]. Increasing physical activity (PA), specifically moderate to vigorous PA (MVPA), is important for the prevention and treatment of childhood

\footnotetext{
* Correspondence: shari.barkin@vanderbilt.edu

${ }^{9}$ Department of Pediatrics, Vanderbilt University School of Medicine, 2200

Children's Way, Doctor's Office Tower 8232, Nashville, TN 37232-9225, USA

Full list of author information is available at the end of the article
}

obesity, health promotion, and beneficial behavioral and academic outcomes [6-10]. This is particularly true for low-income racial/ethnic minority youth. Research has shown that these children have lower odds of meeting PA recommendations $[11,12]$ and higher odds of being overweight or obese $[13,14]$. However, to make specific recommendations on how young children should achieve recommended PA, important data gaps must be addressed. These include understanding MVPA patterns young children engage in rather than simply minutes of MVPA they accumulate, how MVPA patterns evolve as children age, and whether MVPA patterns differ by influencing variables such as gender. Gaining a better understanding of young children's MVPA behavior has the potential to inform intervention strategies and policies to promote MVPA. 
Researchers have begun to explore child PA patterns using accelerometry. PA patterns have been characterized by temporality, such as exploring hourly variability throughout a day or on weekdays compared to weekend days [15-17]. Other studies have defined MVPA patterns by bouts or consecutive minutes above a certain threshold [18-20]. Still others have described PA patterns as the types of activities children are doing, the settings in which these activities are done [21, 22], or by using latent class analysis to define patterns [23, 24]. Most studies focused on older school-aged children. Of the studies that have examined PA patterns in preschool-aged children, most had sample sizes of less than 500 [25]. National data from NHANES demonstrate that boys are more physically active than girls as early as elementary school (6-11 years), and this gender disparity persists into adolescence [26]. Age variations in these patterns have not been studied consistently.

In our prior study of 50 preschool-aged children, we identified 4 specific patterns of MVPA using accelerometry: isolated spurt (IS; 15-60 s bouts of PA, with $>60 \mathrm{~s}$ of inactivity preceding and following the MVPA burst), clustered spurt (CS; multiple 15-60 s bouts of PA with $\leq 60 \mathrm{~s}$ between each), isolated sustained activity (ISA; $>60 \mathrm{~s}$ bout of PA, with $>60 \mathrm{~s}$ of inactivity preceding and following the MVPA burst), and clustered sustained activity (CSA; multiple $>60 \mathrm{~s}$ bouts of PA with $\leq 60 \mathrm{~s}$ between each) [27]. Generalizability of these findings were limited by the small sample size and mostly reflected a convenience sample of largely African-American preschoolers. Thus the present study was designed to characterize MVPA patterns in an ethnically diverse large cohort of 2 to 5 year-old children from low-income families and determine whether these patterns differed by gender and age.

\section{Methods}

\section{Study population and design}

Participants were from two obesity prevention treatment trials with preschool-aged children participating in the Childhood Obesity Prevention and Treatment Research (COPTR) Consortium [28, 29]. A total of 1144 children were enrolled in the Vanderbilt University School of Medicine $(n=610)$ and the University of Minnesota $(n=$ 534) trials. Inclusion criteria included age between 2 and 5 years, healthy, received some type of federal assistance (e.g., WIC), and a BMI percentile $\geq 50$ th. BMI and BMI percentile were calculated using the Center for Disease Control Calculator [30]. The exclusion of children with a BMI <50th percentile allowed inclusion of child participants at-risk for developing obesity. Children were weighed and measured using standard procedures to ensure they met BMI eligibility criterion $(\geq 50$ th and $<95$ th in the Tennessee cohort, and $\geq 50$ th in the Minnesota cohort) $[31,32]$. The study was approved by the Vanderbilt
University and University of Minnesota, Twin Cities Institutional Review Boards. The data for this study derive from baseline data prior to randomization. Further study design can be found in previous COPTR Consortium manuscripts [31, 32].

\section{Physical activity measurement and analysis}

Participants were instructed to wear an ActiGraph GT3X/ GT3X+ accelerometer (ActiGraph, Pensacola, FL) on their right hip for 7 days, including when sleeping and napping. Accelerometry recordings from 7:00 am through 8:59 pm were used to capture the typical daily preschool-aged child wake-time cycle. Adherent wear time criterion was 47 days ( $\geq 3$ weekdays and $\geq 1$ weekend day and a maximum of 7 total days per protocol) with at least $\geq 360$ min of wear time/day.

Raw accelerometry data sampled at $40 \mathrm{~Hz}$ were integrated into 15-s and 60-s epochs for PA intensity categories and assessing wear/non-wear intervals, respectively. Non-wear was defined by an interval of at least 90 consecutive minutes of zero counts/min, with allowance of up to $2 \mathrm{~min}$ of non-zero counts if no counts were detected during both the 30 min upstream and downstream from that interval; any non-zero counts were considered wear time [33]. PA intensity categories were derived using cutpoints for preschool-aged children (<38 for sedentary, $\geq 38-419$ for light, 420-841 for moderate, $\geq 842$ for vigorous, and $\geq 420$ for MVPA all in counts/15-s) [34]. Because we were interested in how combined MVPA was distributed across typical wake-wear hours, only days with $\geq 360 \mathrm{~min}$ of wear between 7:00 am and 8:59 pm were included in analyses. Actigraphy data were processed using the $\mathrm{R}$ statistical package [35]. For each occurrence of MVPA, the number of epochs of continuous MVPA and the number of epochs between instances of MVPA were calculated. Based on these, MVPA was classified into one of four MVPA pattern categories [27]:

1. Isolated Spurt (IS): A single MVPA period $\leq \mathbf{4}$ epochs (1 $\mathrm{min})$ in length with $>4$ epochs of nonMVPA before and after it

2. Isolated Sustained Activity (ISA): A single MVPA period $>4$ epochs $(1 \mathrm{~min})$ in length with $>4$ epochs of non-MVPA before and after it

3. Clustered Spurt (CS): An event comprised of a series of MVPA periods that average $\leq \mathbf{4}$ epochs ( $1 \mathrm{~min}$ ), where there are no periods $\geq 4$ epochs of non-MVPA between periods

4. Clustered Sustained Activity (CSA): An event comprised of a series of MVPA periods that average $>\mathbf{4}$ epochs ( $1 \mathrm{~min}$ ), where there are no periods $\geq 4$ epochs of non-MVPA in between periods. 


\section{Statistical analysis}

Univariate statistics were used to describe sociodemographic variables, anthropometric measures, and variables related to accelerometry among children who met minimum accelerometry criteria $(n=1131, n=599$ Vanderbilt and $n=532$ Minnesota). Bivariate relationships between child age and each of the 4 MVPA patterns were assessed using nonparametric Spearman's correlations. Nonparametric, two-sample, Wilcoxon-Mann-Whitney rank-sum tests were conducted to compare distributional differences between boys and girls on variables that demonstrated non-normality. We conducted $t$-tests of the equality of means for two samples to compare boys and girls on normally distributed variables.

To explore if combining data across the 2 trials was appropriate, the interaction effects of study location with child age and gender were both tested for each of the 4 MVPA patterns. Neither of these interactions were statistically significant for any MVPA pattern ( $p$-values ranged from 0.09 to 0.90$)$, with the exception of the age-location interaction effect for isolated spurt $(B=1.25, p=0.006)$. We concluded that a pooled analysis was appropriate except for the analysis of the relationship between child age and proportion of time in isolated spurt, for which the results are reported separately by study location.

Multivariable linear regression models were used to test the associations of gender and age with percentage of time in each MVPA pattern. Additional regression models were explored to examine the potential relationships of BMI percentile, study location, and use of child care with each MVPA pattern. In these models, study location was represented as a binary indicator variable that accounted for differences between each study location, such as the different BMI percentile eligibility requirements (Vanderbilt $\geq 50$ th to $<95$ th BMI percentile, Minnesota $\geq 50$ th BMI percentile). Child care was a binary variable indicating whether the index child participated in child care. Child care type, frequency, and duration were not clarified for all study participants. All calculations and analyses were conducted using Stata/SE 14.1.

\section{Results}

Of the 1144 study participants, 1131 met minimum accelerometry criteria and were included in this study. These children wore accelerometers for averages of 6.7 $(S D=0.7)$ days and $12.9(S D=1.4)$ hours/day between 7:00 am and 8:59 pm (Table 1).

\section{Demographic and anthropometric characteristics}

Among participating children about half (48.4\%) were males. Mean age was 3.9 (minimum $=2$, maximum $=6$; $S D=0.9)$ years and mean BMI was $17.1 \mathrm{~kg} / \mathrm{m}^{2}(S D=1.4)$. The study population was comprised of Hispanic/Latino (75.6\%), followed by Non-Hispanic Blacks (11.8\%), and
Non-Hispanic Whites (6.5\%). Nearly one-third (29.9\%) of participants were overweight $(\geq 85$ th to $<95$ th BMI percentile) and $11.5 \%$ were obese ( $\geq 95$ th BMI percentile). About $50 \%$ of primary caregivers had less than a high school education. Nearly $60 \%$ of children lived in a household with an annual household income less than $\$ 25,000$. Almost $15 \%$ of families did not know or declined to report household income. About $30 \%$ of children attended child care.

\section{Physical activity \\ PA intensity}

Boys and girls spent about $50 \%$ of their wear time in sedentary behaviors. Statistically significant differences between boys and girls were found in time spent in sedentary behavior and all PA activity intensities (light, moderate, vigorous, and MVPA) (Table 1). On average both boys and girls achieved at least $90 \mathrm{~min}$ of MVPA/day. However, boys spent a greater percentage of wear time in MVPA than girls $(13.6 S D=4.1 \%$ and $11.9 S D=3.6 \%, p<0.001)$, which translated into 13.5 more minutes of MVPA per day $(105.2 S D=33.4 \mathrm{~min}$ and $91.7 S D=29.8 \mathrm{~min}, p<$ 0.001) (Table 1).

\section{MVPA patterns}

On average, children engaged in isolated spurt 44.0, isolated sustained activity 1.1 , clustered spurt 36.5 , and clustered sustained activity 2.6 times/day. There were also small differences between boys and girls in the average number of isolated spurt, isolated sustained activity, and clustered sustained activity events per a typical day (Table 2). When the duration of each MVPA pattern event was examined, differences between boys and girls became more pronounced. Boys engaged in each of the four MVPA patterns for longer when compared to girls (all $p<0.005$ ) (Table 2). Figure 1 illustrates the percent of MVPA/day achieved in MVPA patterns on an average day.

Gender differences Compared to boys, girls spent significantly higher proportion of MVPA in isolated spurt $(18.2 \% S D=5.6 \%$ vs. $15.5 \% S D=5.7 \%)$ and clustered spurt $(64.8 \% S D=6.7 \%$ vs. $62.3 \% S D=8.1 \%)$ (Fig. 1$)$. Boys had a significantly higher proportion of clustered sustained activity compared to girls $(20.0 \% S D=9.5 \%$ vs. $15.0 \% S D=7.9 \%)$. All $p$-values were less than 0.001 .

Age There was a significant correlation between child age and proportion of time spent in the four MVPA patterns. Older children tended to have a greater proportion of MVPA in clustered sustained activity $\left(r_{\mathrm{s}}=0.15, p<0.001\right)$ and isolated sustained activity $\left(r_{\mathrm{s}}=0.10, p<0.001\right)$ and a smaller proportion in clustered spurt $\left(r_{\mathrm{s}}=-0.15, p<\right.$ $0.001)$ and isolated spurt $\left(r_{\mathrm{s}}=-0.07, p=0.02\right)$. 
Table 1 Accelerometer measured average time (min) and \% spent in PA intensity categories

\begin{tabular}{|c|c|c|c|c|c|c|c|}
\hline \multirow[b]{2}{*}{ Adherent accelerometer wear days (day) } & \multirow{2}{*}{$\begin{array}{l}\text { All participants } \\
(n=1131)\end{array}$} & \multirow{2}{*}{$\begin{array}{l}\text { Girls } \\
(n=583) \\
6.6(0.7)\end{array}$} & \multirow{2}{*}{$\begin{array}{l}\text { Boys } \\
(n=548)\end{array}$} & \multirow{2}{*}{$\begin{array}{l}\text { Test } \\
\text { Rank-sum }\end{array}$} & \multirow{2}{*}{$\begin{array}{l}P \text { value }{ }^{1} \\
0.01\end{array}$} & \multicolumn{2}{|c|}{$\begin{array}{l}95 \% \mathrm{Cl} \text { for difference between } \\
\text { boys and girls }\end{array}$} \\
\hline & & & & & & NA & NA \\
\hline Daily wear time (h) & $12.9(1.4)$ & $12.8(1.5)$ & $12.9(1.3)$ & Rank-sum & 0.7 & NA & NA \\
\hline \multicolumn{8}{|l|}{ Sedentary } \\
\hline Mean $\min (s d)$ & $409.9(69.6)$ & $413.0(70.6)$ & $406.5(68.4)$ & T-test & 0.1 & -14.6 & 1.7 \\
\hline$\%$ wear time & $53.2(7.3)$ & $53.7(7.3)$ & $52.7(7.3)$ & T-test & 0.02 & -1.83 & -0.13 \\
\hline \multicolumn{8}{|l|}{ Light } \\
\hline Mean $\min (\mathrm{sd})$ & $263.4(49.0)$ & $265.9(49.5)$ & $260.8(48.4)$ & Rank-sum & 0.048 & NA & NA \\
\hline$\%$ wear time & $34.1(4.9)$ & $34.4(4.8)$ & $33.7(4.9)$ & Rank-sum & 0.008 & NA & NA \\
\hline \multicolumn{8}{|l|}{ Moderate } \\
\hline Mean $\min (s d)$ & $70.6(20.6)$ & $67.6(20.0)$ & $73.8(20.7)$ & T-test & $<0.001^{2}$ & 3.9 & 8.6 \\
\hline$\%$ wear time & $9.2(2.5)$ & $8.8(2.4)$ & $9.6(2.5)$ & T-test & $<0.001$ & 0.51 & 1.08 \\
\hline \multicolumn{8}{|l|}{ Vigorous } \\
\hline Mean min (sd) & $27.6(13.7)$ & $24.2(11.3)$ & $31.3(14.9)$ & Rank-sum & $<0.001$ & NA & NA \\
\hline$\%$ wear time & $3.6(1.7)$ & $3.1(1.4)$ & $4.1(1.9)$ & Rank-sum & $<0.001$ & NA & NA \\
\hline \multicolumn{8}{|l|}{ Moderate + vigorous } \\
\hline Mean min (sd) & $98.2(32.3)$ & $91.7(29.8)$ & $105.2(33.4)$ & Rank-sum & $<0.001$ & NA & NA \\
\hline$\%$ wear time & $12.7(3.9)$ & 11.9 (3.6) & $13.6(4.1)$ & Rank-sum & $<0.001$ & NA & NA \\
\hline
\end{tabular}

Values are means (SD)

${ }^{1} P$ values from non-normally distributed variables are from non-parametric, two-sample, Wilcoxon-Mann-Whitney rank-sum tests of the null hypothesis that the distribution of girls is equal to the distribution of boys. $P$ values from normally distributed variables are from two-sample $t$-tests of the equality of means

${ }^{2}$ Results from rank-sum and $t$-test agreed. T-test results are reported

Table 2 MVPA events/day, duration, and time spent in MVPA within each MVPA pattern event $(N=1131)$

\begin{tabular}{|c|c|c|c|c|c|}
\hline MVPA Pattern & $\begin{array}{l}\text { All Participants } \\
(N=1131)\end{array}$ & $\begin{array}{l}\text { Girls } \\
(N=583)\end{array}$ & $\begin{array}{l}\text { Boys } \\
(N=548)\end{array}$ & Test & $P$ value ${ }^{1}$ \\
\hline \multicolumn{6}{|l|}{ Isolated spurt } \\
\hline Frequency (SD) & $44.0(9.1)$ & $44.9(9.1)$ & $43.1(8.9)$ & Rank-sum & $<0.001$ \\
\hline Duration (SD) & $0.34(0.02)$ & $0.34(0.02)$ & $0.34(0.02)$ & Rank-sum & $0.004^{*}$ \\
\hline \multicolumn{6}{|l|}{ Isolated sustained activity } \\
\hline Frequency (SD) & $1.1(0.6)$ & $1.1(0.5)$ & $1.2(0.6)$ & Rank-sum & $<0.001$ \\
\hline Duration (SD) & $1.73(0.44)$ & $1.69(0.42)$ & $1.76(0.45)$ & Rank-sum & $0.001^{*}$ \\
\hline \multicolumn{6}{|l|}{ Clustered spurt } \\
\hline Frequency (SD) & $36.5(9.6)$ & $36.3(9.8)$ & $36.7(9.3)$ & T-test & 0.4 \\
\hline Duration (SD) & $3.33(0.62)$ & $3.15(0.54)$ & $3.52(0.64)$ & Rank-sum & $<0.001^{*}$ \\
\hline MVPA duration within clustered spurt event & $2.02(0.46)$ & $1.89(0.39)$ & $2.17(0.48)$ & Rank-sum & $<0.001^{*}$ \\
\hline \multicolumn{6}{|l|}{ Clustered sustained activity } \\
\hline Frequency (SD) & $2.6(1.4)$ & $2.2(1.2)$ & $3.0(1.6)$ & Rank-sum & $<0.001$ \\
\hline Duration (SD) & $8.35(2.86)$ & $7.86(2.76)$ & $8.88(2.87)$ & Rank-sum & $<0.001^{*}$ \\
\hline MVPA duration within clustered sustained activity event & $6.69(2.29)$ & $6.28(2.18)$ & $7.12(2.33)$ & Rank-sum & $<0.001^{*}$ \\
\hline
\end{tabular}

*Represents statistically significant $P$ values that are $<0.05$

Values are mean (SD); Moderate-to-vigorous physical activity (MVPA)

${ }^{1} P$ values from non-normally distributed variables are from non-parametric, two-sample, Wilcoxon-Mann-Whitney rank-sum tests of the null hypothesis that the distribution of girls is equal to the distribution of boys. $P$ values from normally distributed variables are from two-sample $t$-tests of the equality of means 


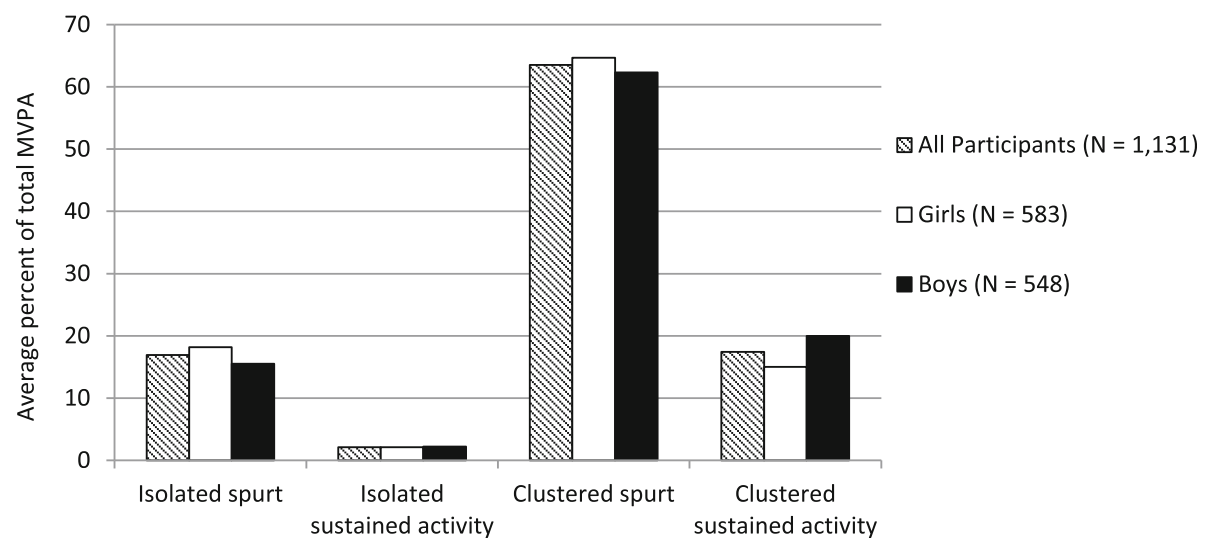

Fig. 1 Average percent of total MVPA achieved through each specific pattern type $(N=1131)$. Because the distributions of all PA categories were non-normal, the following $p$-values are from non-parametric, two-sample, Wilcoxon-Mann-Whitney rank-sum tests of the null hypothesis that the distribution of girls is equal to the distribution of boys: IS $p<0.001$, ISA $p=0.2$, CS $p<0.001$, CSA $p<0.001$

Gender and age Controlling for age, girls spent an average of $2.4 \%$ more MVPA time in clustered spurt than boys $(p<0.001,95 \% \mathrm{CI}$ for mean difference $1.52,3.24)$. Controlling for gender, a 1-year increase in age corresponded to a $1.34 \%$ decrease $(p<0.001 ; 95 \%$ CI for mean difference $0.88,1.81$ ) in the proportion of MVPA time spent in clustered spurt (Table 3).

Compared to boys, girls spent an average of 2.4 (VU)$3.0(\mathrm{MN}) \%$ more MVPA time in isolated spurt than boys $(p<0.001 ; 95 \%$ CI 2.09, 3.96 (VU) versus 1.51, 3.6 $(\mathrm{MN}))$. A 1 -year increase in age corresponded to a $1.3 \%$ decrease in the proportion of MVPA time in isolated spurt at MN, but no relationship was detected at VU. Boys spent on average 5.0\% more MVPA time in clustered sustained activity than girls $(p<0.001 ; 95 \% \mathrm{CI}$ for mean difference 4.01, 6.02). A 1-year increase in age corresponded to a $1.5 \%$ increase in the proportion of MVPA time spent in clustered sustained activity $(p<0.001 ; 95 \%$ CI for mean difference 1.00, 2.09).

BMI percentile, study location, and child care Regression models identical to those explored for gender and age were also explored with the addition of covariates for BMI, study location, and child care. None of these covariates were statistically significant, nor did their inclusion change the interpretations of the models.

\section{Discussion}

The aim of this study was to assess the prevalence and frequency of novel MVPA patterns (isolated spurt, clustered spurt, isolated sustained activity, clustered sustained activity) in a large sample of typically developing preschool-aged children from socioeconomically disadvantaged families at-risk for obesity. In our study, the majority of children achieved the National Academy of Medicine recommendation of at least $3 \mathrm{~h} /$ day of total PA including at least 90 min of MVPA, but how they obtained it varied depending on the gender and age of the child. Boys obtained 13.5 more minutes of MVPA per day than girls, which translated to an additional $94.5 \mathrm{~min} /$ week. This seemingly small daily difference could have differential health impacts and should be further assessed. Boys and girls also differed in the relative amount of time they spent in each MVPA pattern. While girls spent a statistically significant greater proportion of their MVPA time in spurt-like MVPA patterns, boys spent a statistically significant greater proportion of their MVPA time in sustained MVPA patterns.

Table 3 Linear associations of child gender and age with time spent in each PA pattern category

\begin{tabular}{llllllccc}
\hline $\begin{array}{l}\text { PA pattern category } \\
\text { (MVPA \%) }\end{array}$ & Gender coefficient & Gender $p$ value & $95 \% \mathrm{Cl}$ & & Age coefficient & Age $p$ value & $95 \% \mathrm{Cl}$ \\
\hline Isolated spurt \% (MN) & & & & & & & \\
Isolated spurt \% (VU) & 3.02 & $<0.001$ & 2.09 & 3.96 & -1.32 & $<0.001^{*}$ & -2.03 & -0.60 \\
Isolated sustained activity \% (pooled) & -0.11 & 0.1 & 1.51 & 3.36 & -0.07 & 0.8 & -0.59 & 0.45 \\
Clustered spurt \% (pooled) & 2.38 & -0.25 & 0.04 & 0.18 & $<0.001^{*}$ & 0.10 & 0.26 \\
Clustered sustained activity \% (pooled) & -5.01 & $<0.001$ & 1.52 & 3.24 & -1.34 & $<0.001^{*}$ & -1.81 & -0.88 \\
\hline
\end{tabular}

*Represents statistically significant $P$ values that are $<0.05$

${ }^{a}$ Represents estimated change from male to female; Moderate-to-vigorous physical activity (MVPA)

$\mathrm{b}$ Isolated spurt results are reported separately by study location because of a significant study location-by-age interaction effect $(B=1.25, p=0.006)$ 
In particular, boys and girls differed in the average duration of a single MVPA pattern, specifically in the clustered spurt and clustered sustained activity categories. A clustered spurt event for boys averaged an additional $22 \mathrm{~s}$ in duration (17 of which were MVPA) when compared to girls. This seemingly small time difference, when accumulated throughout the day, translated to about 10 more minutes of MVPA for boys from this MVPA pattern alone. Additionally, a clustered sustained activity event for boys averaged an additional $61 \mathrm{~s}$ in duration (50 of which were MVPA) when compared to girls; this translates to an additional $7 \mathrm{~min}$ of MVPA for boys on average. These findings are promising since research among preschool-aged children have found an inverse relationship between physical activity and BMI [36]. Furthermore, children that demonstrated high-intensity physical activity were less likely to be overweight and exhibit body fatness during the adiposity rebound period of childhood growth [37,38]. Additionally, these findings could give us insight into the gender gap that emerges in older children [39].

PA is associated with a number of health benefits in youth, regardless of their BMI status [40]. The literature provides support for a relationship between greater PA and favorable health outcomes such as adiposity, bone and skeletal health, psychosocial health, cognitive development, and cardiometabolic health among children 4-years and younger [41]. Literature remains largely inconclusive regarding whether a significant difference exists in the daily amount of MVPA between preschool-aged boys and girls [16, 27, 42-44]. In our study, we did find significant differences of about $6.2 \mathrm{~min} /$ day of moderate $\mathrm{PA}$ and $7.1 \mathrm{~min} /$ day of vigorous PA between boys and girls. Girls were active, but spent less time in MVPA and less time in sustained patterns of MVPA (isolated sustained activity, clustered sustained activity). The importance of studying MVPA in preschool-aged children extends beyond establishing whether or not the recommended daily level is achieved. Examining PA through these novel MVPA patterns may contribute to our understanding of the inherent differences between boys and girls.

It has been estimated that about $61 \%$ of children under 5 years of age in the US attend some form of child care regularly during a typical week [45]. Child care arrangements have been shown to vary greatly in the amount of MVPA children obtain during their care [46, 47]. Among our study cohort, no difference in percentage of time in any MVPA pattern was detected between children who attended child care and those who did not. More research is needed to examine whether the structure of daycare time allotted to PA can enhance time spent in MVPA.

In one particular study that looked at outdoor free time among preschoolers, children were noted to be more active in the first 10-15 min of playtime compared to the last 1015 min of playtime. The 3 year-old participants had a more significant difference between first and last minutes of playtime compared to their 4 and 5 year-old counterparts [48]. Our current study found that among preschoolers, each additional year of age was associated with less time in spurt-like activity and more time in sustained activity. This finding aligns with our a priori hypothesis about the relationship between age and sustained and spurt-like activity, and it also supports the suggestion that older preschool-aged children are active for longer periods of time compared to younger preschoolaged children. If we take these results to illustrate the child development and associated PA behaviors of preschoolaged children, it follows that short duration PA activities (< $15 \mathrm{~min}$ ) offered at several times throughout the day might help children maximize their MVPA. The novel findings reported in this study could allow us to examine new hypotheses to influence PA practices and policies for young children.

\section{Limitations}

Despite our extremely compliant large cohort of preschoolaged children who provided us with a robust dataset for analysis, some limitations exist. By study design, we did not examine PA in any child under the 50th BMI percentile. Our study cohort was predominately comprised of Hispanic/Latino children from low SES households. Thus, we cannot generalize our data to children from higher socioeconomic status, who are white, or whose BMI percentile is $<50$ th. In our study, a participant's neighborhood environment was not controlled for in our statistical analysis, and thus could be a potential confounder. Additionally, we did not have the ability to distinguish sedentary behaviors from sleep, so we could not make any conclusions about sedentary behavior; however, that was not the intention of this study. Lastly, this was a cross-sectional study; thus, we could only look at correlations not causation.

\section{Conclusions}

Most underserved minority preschool-aged children in this cohort obtained the current daily recommended amount of MVPA during their waking day. However boys and girls achieved this recommendation through different patterns of MVPA, girls through more spurtlike PA and boys through more sustained PA. Within the preschool-aged population, each additional year in age was associated with less time spent in spurt-like patterns of PA and more time spent in sustained patterns of PA. If these patterns persist as children age, these differences could, in part, explain the gender gap in MVPA.

\section{Abbreviations}

BMI: Body Mass Index; COPTR: Childhood Obesity Prevention and Treatment Research; CS: Clustered Spurt; CSA: Clustered Sustained Activity; IS: Isolated Spurt; ISA: Isolated Sustained Activity; MVPA: Moderate to Vigorous Physical Activity; PA: Physical activity 


\section{Acknowledgements}

We are grateful to the participants in the GROW and NET-Works trials and also acknowledge the hard work of the study teams at the Vanderbilt University Medical Center, the University of Minnesota, and the University of North Carolina- Chapel Hill that allowed for the high quality data collection and analysis required for this work.

\section{Funding}

This research was supported by grants (U01 HL103620; U01 HD068890) with additional support from the remaining members of the COPTR Consortium (U01 HL103561) from the National Heart, Lung, and Blood Institute and the Eunice Kennedy Shriver National Institute of Child Health and Development and the Office of Behavioral and Social Sciences Research. The content is solely the responsibility of the authors and does not necessarily represent the official views of the National Heart, Lung, And Blood Institute, the National Institutes of Health, or the National Institute of Child Health and Development. This research was also supported by the P30 Grant: 2P30DK092986-07. The REDCap Database is supported by NCATS/NIH, UL1 TR000445.

\section{Availability of data and materials}

The datasets generated during and/or analysed during the current study will be made available to the public no later than 3 years after the end of $\mathrm{NIH}$ support.

\section{Authors' contributions}

SB conceptualized and designed the study. RR, ES, and DT analyzed the data. $\mathrm{KE}, \mathrm{MB}, \mathrm{CE}, \mathrm{JB}$, and $\mathrm{MJ}$ critically reviewed and wrote the manuscript. All authors edited and proofed the paper. All authors read and approved the final manuscript.

\section{Ethics approval and consent to participate}

Written informed consent was obtained prior to participation and protocols were approved by the Vanderbilt University (No. 120643) and the University of Minnesota (No. 1005S81634) Institutional Review Boards.

\section{Consent for publication}

Not applicable.

\section{Competing interests}

The authors declare that they have no competing interests.

\section{Publisher's Note}

Springer Nature remains neutral with regard to jurisdictional claims in published maps and institutional affiliations.

\footnotetext{
Author details

${ }^{1}$ Division of Pediatric Gastroenterology, Hepatology, and Nutrition, Stanford University School of Medicine, 750 Welch Road, Suite 116, Palo Alto, CA 94304, USA. ²Department of Pediatrics, Vanderbilt University Medical Center, 2146 Belcourt Ave, Nashville, TN 37232-9225, USA. ${ }^{3}$ Department of Economics, Andrew Young School of Policy Studies, Georgia State University, 14 Marietta St, Atlanta, GA 30303, USA. ${ }^{4}$ Stanford Prevention Research Center, Stanford University School of Medicine, Medical School Office Building, 1265 Welch Road, Room X1C39, Stanford, CA 94305-5415, USA. ${ }^{5}$ Friedman School of Nutrition Science and Policy, Tufts University, Jaharis Family Center for Biomedical and Nutrition Sciences, 150 Harrison Ave, Boston, MA 02111, USA. ${ }^{6}$ Division of Epidemiology and Community Health, School of Public Health, University of Minnesota, 1300 S 2nd St., Suite 300, Minneapolis, MN 55454-1015, USA. 'Department of Epidemiology, The University of North Carolina at Chapel Hill Gillings School of Global Public Health, 137 East Franklin Street, Suite 306, CVS Plaza, CB \#8050, Chapel Hill, NC 27514, USA ${ }^{8}$ Division of Gastroenterology, Hepatology, \& Nutrition, Vanderbilt University Medical Center, 2215 Garland Ave, A4103 MCN, Nashville, TN 37232-5280, USA. ${ }^{9}$ Department of Pediatrics, Vanderbilt University School of Medicine, 2200 Children's Way, Doctor's Office Tower 8232, Nashville, TN 37232-9225, USA
}

Received: 13 January 2017 Accepted: 31 January 2018

Published online: 13 February 2018

\section{References}

1. Institute of Medicine Early childhood obesity prevention policies. Institute of Medicine, 2011

2. DoHa A. National physical activity guidelines for Australians. Physical activity recommendations for 0-5 year olds. Canberra: Commonwealth of Australia; 2010.

3. Department of Health PA, Health improvement and protection. Start active, stay active: A report on physical activity for health from the four home countries' chief medical officers. London: Department of Health; 2011.

4. Canadian Society for Exercise Physiology. Canadian physical activity guidelines and Canadian sedentary behaviour guidelines: your plan to get active every day 2012 [16 Feb 2016]. Available from: http://www.csep.ca/en/ publications/view-publications.

5. Pate RR, O'Neill JR, Brown WH, Pfeiffer KA, Dowda M, Addy CL. Prevalence of compliance with a new physical activity guideline for preschool-age children. Child Obes. 2015;11(4):415-20.

6. Lambourne K, Donnelly JE. The role of physical activity in pediatric obesity. Pediatr Clin N Am. 2011:58(6):1481-91. xi-xii

7. Janssen I, Leblanc AG. Systematic review of the health benefits of physical activity and fitness in school-aged children and youth. Int J Behav Nutr Phys Act. 2010;7:40

8. Brambilla P, Pozzobon G, Pietrobelli A. Physical activity as the main therapeutic tool for metabolic syndrome in childhood. Int J Obes. 2011;35(1):16-28.

9. Flynn MA, McNeil DA, Maloff B, Mutasingwa D, Wu M, Ford C, et al. Reducing obesity and related chronic disease risk in children and youth: a synthesis of evidence with 'best practice' recommendations. Obes Rev. 2006;7(Suppl 1):7-66.

10. Physical Activity Guidelines Advisory Committee. Physical activity guidelines advisory committee report, 2008. Washington, DC: U.S. Department of Health and Human Services; 2008. Contract No.: A1-H14

11. Fakhouri TH, Hughes JP, Brody DJ, Kit BK, Ogden CL. Physical activity and screen-time viewing among elementary school-aged children in the United States from 2009 to 2010. JAMA Pediatr. 2013:167(3):223-9.

12. Anderson SE, Economos CD, Must A. Active play and screen time in US children aged 4 to 11 years in relation to sociodemographic and weight status characteristics: a nationally representative cross-sectional analysis. BMC Public Health. 2008:8:366.

13. Ogden $\mathrm{CL}$, Carroll MD, Kit BK, Flegal KM. Prevalence of childhood and adult obesity in the United States, 2011-2012. JAMA. 2014;311(8):806-14.

14. Belcher BR, Berrigan D, Dodd KW, Emken BA, Chou CP, Spruijt-Metz D. Physical activity in US youth: effect of race/ethnicity, age, gender, and weight status. Med Sci Sports Exerc. 2010:42(12):2211-21.

15. De Baere S, Lefevre J, De Martelaer K, Philippaerts R, Seghers J. Temporal patterns of physical activity and sedentary behavior in 10-14 year-old children on weekdays. BMC Public Health. 2015;15:791.

16. Van Cauwenberghe E, Jones RA, Hinkley T, Crawford D, Okely AD. Patterns of physical activity and sedentary behaviour in preschool children. Int J Behav Nutr Phys Act. 2012:9:138.

17. O'Dwyer M, Fairclough SJ, Ridgers ND, Knowles ZR, Foweather L, Stratton G. Patterns of objectively measured moderate-to-vigorous physical activity in preschool children. J Phys Act Health. 2014;11(6):1233-8.

18. Benham-Deal T. Preschool children's accumulated and sustained physical activity. Percept Mot Skills. 2005:100(2):443-50.

19. Cliff DP, Jones RA, Burrows TL, Morgan PJ, Collins CE, Baur LA, et al. Volumes and bouts of sedentary behavior and physical activity: associations with cardiometabolic health in obese children. Obesity (Silver Spring). 2014:22(5):E112-8.

20. Johansson E, Hagstromer M, Svensson V, Ek A, Forssen M, Nero H, et al. Objectively measured physical activity in two-year-old children - levels, patterns and correlates. Int J Behav Nutr Phys Act. 2015;12:3.

21. Biddle SJ, Marshall SJ, Gorely T, Cameron N. Temporal and environmental patterns of sedentary and active behaviors during adolescents' leisure time. Int J Behav Med. 2009;16(3):278-86.

22. Senso MM, Trost SG, Crain AL, Seburg EM, Anderson JD, Sherwood NE. Activity patterns of preschool-aged children at risk for obesity. J Phys Act Health. 2015:12(6):861-8.

23. Kim Y, Barreira TV, Kang M. Concurrent associations of physical activity and screen-based sedentary behavior on obesity among US adolescents: a latent class analysis. J Epidemiol. 2016;26(3):137-44. 
24. Evenson KR, Wen F, Hales D, Herring AH. National youth sedentary behavior and physical activity daily patterns using latent class analysis applied to accelerometry. Int J Behav Nutr Phys Act. 2016;13(1):55.

25. Tonge $\mathrm{KL}$, Jones RA, Okely AD. Correlates of children's objectively measured physical activity and sedentary behavior in early childhood education and care services: a systematic review. Prev Med. 2016;89:129-39.

26. Troiano RP, Berrigan D, Dodd KW, Masse LC, Tilert T, McDowell M. Physical activity in the United States measured by accelerometer. Med Sci Sports Exerc. 2008;40(1):181-8.

27. Ruiz RM, Tracy D, Sommer EC, Barkin SL. A novel approach to characterize physical activity patterns in preschool-aged children. Obesity (Silver Spring). 2013;21(11):2197-203.

28. Pratt CA, Boyington J, Esposito L, Pemberton VL, Bonds D, Kelley M, et al. Childhood obesity prevention and treatment research (COPTR): interventions addressing multiple influences in childhood and adolescent obesity. Contemp Clin Trials. 2013;36(2):406-13.

29. Stevens J, Pratt C, Boyington J, Nelson C, Truesdale KP, Wards DS, et al. Multilevel Interventions Targeting Obesity: Research recommendations for vulnerable populations. Am J Prev Med. 2017;52(1):115-24.

30. Centers for Disease Control and Prevention. BMI Calculator for Child and Teen: English Version [cited 6 Dec 2007]. Available from: https://nccd.cdc. gov/dnpabmi/Calculator.aspx.

31. Po'e EK, Heerman WJ, Mistry RS, Barkin SL. Growing right onto wellness (GROW): a family-centered, community-based obesity prevention randomized controlled trial for preschool child-parent pairs. Contemp Clin Trials. 2013;36(2):436-49

32. Sherwood NE, French SA, Veblen-Mortenson S, Crain AL, Berge J, KuninBatson A, et al. NET-works: linking families, communities and primary care to prevent obesity in preschool-age children. Contemp Clin Trials. 2013;36(2): 544-54

33. Choi L, Ward SC, Schnelle JF, Buchowski MS. Assessment of wear/nonwear time classification algorithms for triaxial accelerometer. Med Sci Sports Exerc. 2012;44(10):2009-16

34. Pate RR, O'Neill JR, Mitchell J. Measurement of physical activity in preschool children. Med Sci Sports Exerc. 2010;42(3):508-12.

35. Choi L., Zhouwen L., Matthews C.E., Buchowski M.S. Process physical activity accelerometer data. 2011.

36. Brasholt $M$, Chawes B, Kreiner-Moller E, Vahlkvist S, Sinding M, Bisgaard H. Objective assessment of levels and patterns of physical activity in preschool children. Pediatr Res. 2013;74(3):333-8.

37. Vale SM, Santos RM, Da Cruz Soares-Miranda LM, Moreira CM, Ruiz JR, Mota JA. Objectively measured physical activity and body mass index in preschool children. Int J Pediatr. 2010;2010:479439.

38. Janz KF, Levy SM, Burns TL, Torner JC, Willing MC, Warren JJ. Fatness, physical activity, and television viewing in children during the adiposity rebound period: the lowa bone development study. Prev Med. 2002;35(6): 563-71.

39. Trost SG, Pate RR, Sallis JF, Freedson PS, Taylor WC, Dowda M, et al. Age and gender differences in objectively measured physical activity in youth. Med Sci Sports Exerc. 2002;34(2):350-5.

40. Physical Activity Guidelines Advisory Committee. Physical activity guidelines advisory committee report, 2008. Washington, D. C: U.S. Department of Health and Human Services; 2008.

41. Timmons BW, Leblanc AG, Carson V, Connor Gorber S, Dillman C, Janssen I, et al. Systematic review of physical activity and health in the early years (aged 0-4 years). Appl Physiol Nutr Metab. 2012;37(4):773-92.

42. Hesketh KR, McMinn AM, Ekelund U, Sharp SJ, Collings PJ, Harvey NC, et al, Objectively measured physical activity in four-year-old British children: a cross-sectional analysis of activity patterns segmented across the day. Int $J$ Behav Nutr Phys Act. 2014;11(1)

43. Jackson DMRJ, Kelly LA, Montgomery C, Grant S, Paton JY. Objectively measured physical activity in a representative sample of 3- to 4-year-old children. Obes Res. 2003;11(3):420-5.

44. van Sluijs EM, McMinn AM, Inskip HM, Ekelund U, Godfrey KM, Harvey NC, et al. Correlates of light and moderate-to-vigorous objectively measured physical activity in four-year-old children. PLoS One. 2013; 8(9):e74934.

45. Laughlin L. Who's Minding the Kids? Child Care Arrangements: Spring 2011. Washington, DC: U.S. Census Bureau; 2013 April 2013. Report No. p. 70-135.
46. Rice KR, Trost SG. Physical activity levels among children attending family day care. J Nutr Educ Behav. 2014;46(3):197-202.

47. Pate RR, O'Neill JR, Byun W, Mclver KL, Dowda M, Brown WH. Physical activity in preschool children: comparison between Montessori and traditional preschools. J Sch Health. 2014;84(11):716-21.

48. Greever CJ, Sirard J, Alhassan S. Objective analysis of Preschoolers' physical activity patterns during free playtime. J Phys Act Health. 2015;12(9):1253-8.

\section{Submit your next manuscript to BioMed Central and we will help you at every step:}

- We accept pre-submission inquiries

- Our selector tool helps you to find the most relevant journal

- We provide round the clock customer support

- Convenient online submission

- Thorough peer review

- Inclusion in PubMed and all major indexing services

- Maximum visibility for your research

Submit your manuscript at www.biomedcentral.com/submit
Biomed Central 